\title{
T-helper 1 Immune Response in Systemic Lupus Erythematosus and its Relation to Disease Activity
}

\author{
Tarek A Ghonemy ${ }^{\mathrm{a}^{*}}$, Ebrahim M Salim ${ }^{\mathrm{b}}$, Yasser A Al-Hendi ${ }^{\mathrm{b}}$, Amir El Okely ${ }^{\mathrm{b}}$ \\ a. University Hospital Birmingham, UK \\ b. Faculty of medicine, Zagazig University, Egypt
}

\begin{abstract}
Introduction: Systemic lupus erythematosus (SLE) is a prototypic systemic autoimmune disease characterized by various immunological abnormalities, including dysregulated activation of both $\mathrm{T}$ and $\mathrm{B}$ lymphocytes. The etiology of this immunological disorder has not been clearly elucidated. Aberrant production and imbalance of T-helper (Th) cell cytokines have been implicated in the pathogenesis of autoimmunity. The aim of this study is to evaluate the level of Th1 cytokines interleukin-18 (IL-18) and osteopontin (OPN) in SLE patients and their correlation with the disease activity.
\end{abstract}

Methods: The study included 24 patients with SLE and 20 age- and sex- matched control subjects. The disease activity was evaluated with the SLE disease activity index (SLEDAI). Plasma OPN and IL-18 concentrations were measured in patients and control groups using an enzyme linked immunosorbent assay.

Results: Plasma OPN and IL-18 concentrations were significantly higher in SLE patients than in the control group ( $\mathrm{P}<0.001)$. OPN and IL-18 concentrations correlated positively and significantly with SLEDAI scores in SLE patients $(r=0.831, \mathrm{P}<0.001$ and $\mathrm{r}=0.826$, $\mathrm{P}<0.001$ respectively). In addition, there was a highly significant positive correlation between OPN and IL-18 levels $(\mathrm{r}=0.75, \mathrm{P}<0.001)$.

Conclusion:ThecirculatingIL-18andOPNconcentrations were significantly elevated in SLE patients and correlated with the SLEDAI score. This suggests a crucial role for Th1 cytokines in the inflammatory processes and tissue damage in SLE disease. Both cytokines my act as potential disease markers for monitoring of SLE disease activity and therapeutic efficacy.

\footnotetext{
* Corresponding author; Univerisity Hospital Birmingham, UK.

E mail: tarekghonemy@hotmail.com
}

Keywords: SLE, Th-1, SLEDAI, osteopontin, IL-18.

\section{Introduction}

Systemic lupus erythematosus (SLE) is a prototypic systemic autoimmune disease characterized by various immunological abnormalities, including dysregulated activation of both $\mathrm{T}$ and $\mathrm{B}$ lymphocytes with the production of a large quantity of auto-reactive antibodies and the formation of immune complexes causing tissue and organ damage [1-2]. In some patients, skin rash and joint pain predominate, while in others glomerulonephritis is the main lesion [2]. The etiology and pathogenic mechanism of this immunological disorder have not been clearly elucidated. Aberrant production and imbalance of T-helper (Th) cell cytokines have been implicated in the pathogenesis of autoimmunity [3].

Wong et al demonstrated that the plasma concentration of proinflammatory cytokine interleukin-18 (IL-18) was significantly elevated in SLE patients compared to controls [4]. IL-18 is a pro-inflammatory cytokine, predominantly released by antigen presenting cells such as macrophages and dendritic cells. IL-18 acts as a Th1 cytokine since it promotes both proliferation of Th1 lymphocytes and IFN-gamma production by these cells [5]. It plays an important role in innate immunity and shares functional similarities with IL-12 which induces the production of IL-18 by activation of natural killer cells (NK) and cytotoxic T lymphocytes (CTL) [6].

Human IL-receptor protein is a functional component of IL-18 receptors. IL-18 receptors are selectively expressed on murine Th1 cells but not Th2 cells [7]. The primary function of IL-18 includes the induction of IFN-gamma and TNF-alpha in T cells and NK cells, the up-regulation of Th1 cytokines, including IL-2, granulocytesmacrophage colony stimulating factor (GM-CSF) and IFN-gamma, stimulation of proliferation of activated $\mathrm{T}$ cells and the enhancement of Fas ligand expression in NK cells and CTL [7]. 
Table 1: SLE disease activity index (SLEDAI)

\begin{tabular}{ll}
\hline Score & Item \\
\hline 8 & Seizure, psychosis, organic brain syndrome, visual disturbance, cranial nerve disorder, lupus headache, CVA, vasculitis \\
4 & Arthritis, myositis, urinary casts, hematuria, proteinuria, and pyuria \\
2 & Rash, alopecia, mucosal ulcers, pleurisy, pericarditis, low complement, high DNA \\
1 & Fever, low platelets, low WBC \\
\hline
\end{tabular}

Table 2: Patients' laboratory and demographic data

\begin{tabular}{lll}
\hline Patient characteristic & Range & Mean \pm SD \\
\hline Age & $14-50$ years & $26.9 \pm 8.4$ years \\
Duration of disease & 6 months to 10 years & $3.4 \pm 1.7$ years \\
S. Creatinine & $0.8-1.6 \mathrm{mg} / \mathrm{dl}$ & $1.2 \pm 0.19 \mathrm{mg} / \mathrm{dl}$ \\
SLEDAI Score & $4-30$ & $17.5 \pm 7.7$ \\
\hline
\end{tabular}

Osteopontin (OPN) is a phosphorylated glycoprotein secreted by the activated macrophages, leukocytes and activated $\mathrm{T}$ lymphocytes. It is present in extra cellular fluids, at sites of inflammation, and in the extra cellular matrix of mineralized tissues [8].

During inflammation, OPN is expressed by cells of both innate and adaptive immunity, such as NK cells, activated $\mathrm{T}$ cells, macrophages and resident fibroblasts [9]. OPN is also called early T-lymphocyte activation protein 1 (Eta-1) because of its early production upon cell activation, and has been shown to enhance Th1 but inhibit Th2 response [10].

Among multiple receptors for OPN, CD44 is the most characterized receptor that appears to mediate the cell chemotaxis [11]. Also, it plays various biological roles for host defense, bone formation, osteoclast activation and wound healing [12]. Its cytokine activities include the stimulation of macrophage and T-cell migration [12], protection against herpes viruses and bacterial infections through the activation of the Th1 response [10], and induction of Th1-cell-mediated autoimmunity [8].

Increased plasma concentration, protein expression and local production of OPN have been observed in sepsis [13], metastasis [14], multiple sclerosis [15], autoimmune/lymphoproliferative syndrome [16], renal tissue of SLE patients [17] and rheumatoid joints of patients with rheumatoid arthritis [18]. However, the circulating level and ex vivo production of OPN in SLE patients and its correlation with disease severity has not been well defined [19].

The aim of this work is to study the level of Th1 cytokine Interleukin-18 (IL-18) and Oseteopontin (OPN) in SLE patients and to study its possible correlation with disease activity.

\section{Methods}

The present study was carried out in the Renal and Vasculitis unit in University Hospital Birmingham, UK, on 24 SLE patients and 20 matched controls. The studied groups were subjected to full history taking, general examination, clinical activity scoring, routine laboratory analysis (ESR, CBC, ANA) and urine analysis. Their disease activity was evaluated with the SLE disease activity index (SLEDAI) [20]. The score comprises 24 weighted components grouped into four categories, evaluated over a time frame of 10 days (Table 1). Change in SLEDAI score of three points or more to a level of eight or more indicates mild to moderate flare or persistent disease activity. Change in SLEDAI score of twelve points or more indicates severe flare.

Twenty millimeters of EDTA preserved venous peripheral blood were collected from each patients and control subject, samples were preserved at $-70^{\circ}$ until used for cytokine assay.

Measurement of IL-18 was done using the human bioactive IL-18 ELISA kit of medical biological laboratories (Nagoya, Japan), code No 7620, according to the manufacturer's instructions. The human IL-18 ELISA kit measures human IL-18 by sandwich ELISA. The assay uses two monoclonal antibodies against two different epitopes of human IL-18.

Quantification of OPN was done using enzyme immunometric assay kit, assay design MI, USA (Catalog No. 900-142). The kit uses two monoclonal antibodies to human OPN; one is immobilized on a microtiter plate to 
Figure 1: Plasma IL-18 concentration in SLE patients and controls

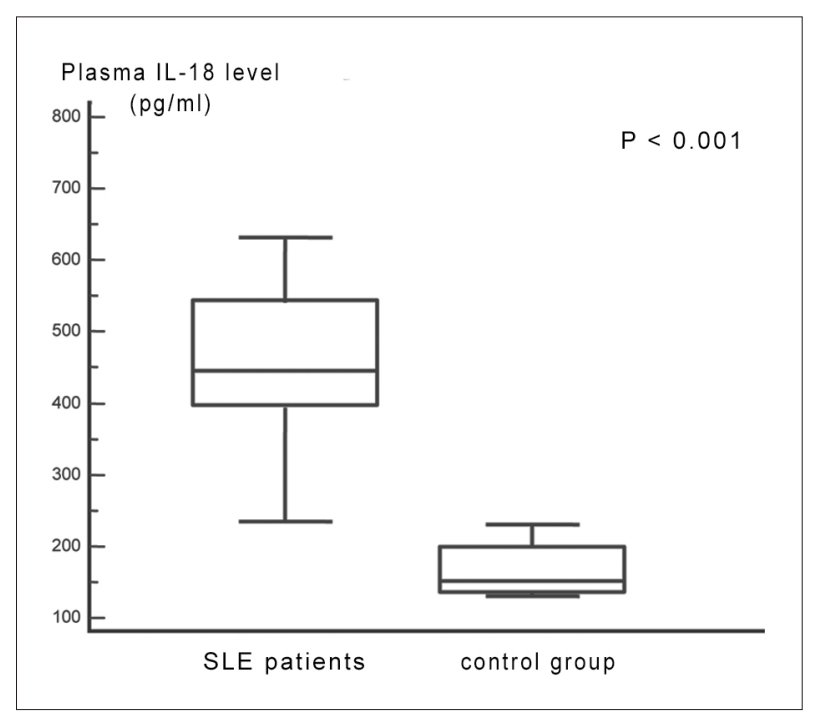

bind human OPN in the standards or samples. The other antibody is a biotinylated monoclonal antibody to human OPN. The manufactures instructions were followed and OPN concentration in the samples was determined by interpolation from standard curve.

Statistical analysis was done using Statistical Package for Social Science version 10.0 for Windows (SPSS, Inc., Chicago, IL, USA). The data were presented in the form of mean + standard deviation (SD). Student ( $t$ ) test was used for comparison of quantitative data. Spearman Rank correlation coefficient was done to study the relation between variables in each group. Significance was considered when $P$ value was less than 0.05 .

\section{Results}

The SLE group consisted of 20 females and four males; their age ranged from 14-50 years with a mean value of $26.9 \pm 8.4$ years. The duration of the disease ranged from 6 months to 10 years with a mean value of $3.4 \pm$ 1.7 years (Table 2). The diagnosis of SLE was according to the 1982 revised American Rheumatism Association Criteria [21].

The control group consisted of 15 females and five males; their age ranged from 15 - 50 years with a mean value of $27.1 \pm 8.6$ years.

The concentration of cytokine IL-18 was significantly higher in SLE patients than the control group (471.1 \pm 140.2 versus $155.4 \pm 35.7 \mathrm{pg} / \mathrm{ml}, \mathrm{P}<0.001$ ) (Figure 1). There was also significant correlation between plasma IL-18
Figure 2: Plasma OPN concentration in SLE patients and controls

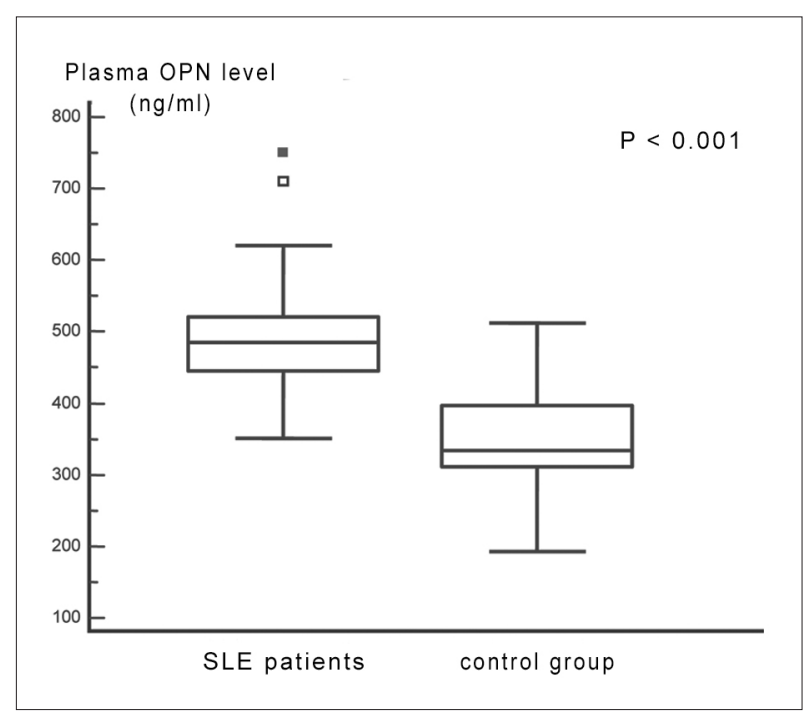

concentrations and SLE disease activity score $(r=0.826$, $\mathrm{P}<0.001)$.

The concentration of OPN was significantly higher in SLE patients than control group (483.33 \pm 118.35 versus $350 \pm 67.67 \mathrm{ng} / \mathrm{ml}, \mathrm{P}<0.001$ ) (Figure 2). There was also highly significant correlation between plasma OPN and SLE disease activity $(\mathrm{r}=0.831, \mathrm{P}<0.001)$ (Figure 3$)$.

In addition, there was a highly significant positive correlation between plasma levels of OPN and IL-18 ( $\mathrm{r}=$ $0.75, \mathrm{P}<0.001)$.

\section{Discussion}

SLE has been postulated to be an autoantibody, immune complex and Th2 cytokine mediated disease [22]. However, previous studies have reported different results for the correlation of the Th1/Th2 ratio with SLE disease activity. One study showed a positive and significant correlation of this ratio with SLEDAI score using in vitrostimulated peripheral blood mononeuclear cells (PBMC) [23]. Another study reported a negative correlation between the ratio of IFN-alpha/IL-10 secreting cells and disease activity as measured by enzyme-linked immunospot analysis of freshly isolated PBMC [24]. Animal experiments using autoimmune mice found that the ratio of Th1/Th2 cytokine mRNA expression of IL-2 and IL-4, IFN-alpha and IL-10 in polymorphonuclear neutrophils and PBMC exhibited a reciprocal relationship with disease severity [25]. However, several clinical studies have indicated that elevation in Th1 cytokines, including IL-12 [26], TNF-alpha [27] and IFN-gamma [28] can mediate the inflammatory processes that lead to 
Figure 3: Correlation between plasma OPN level and SLEDAI score

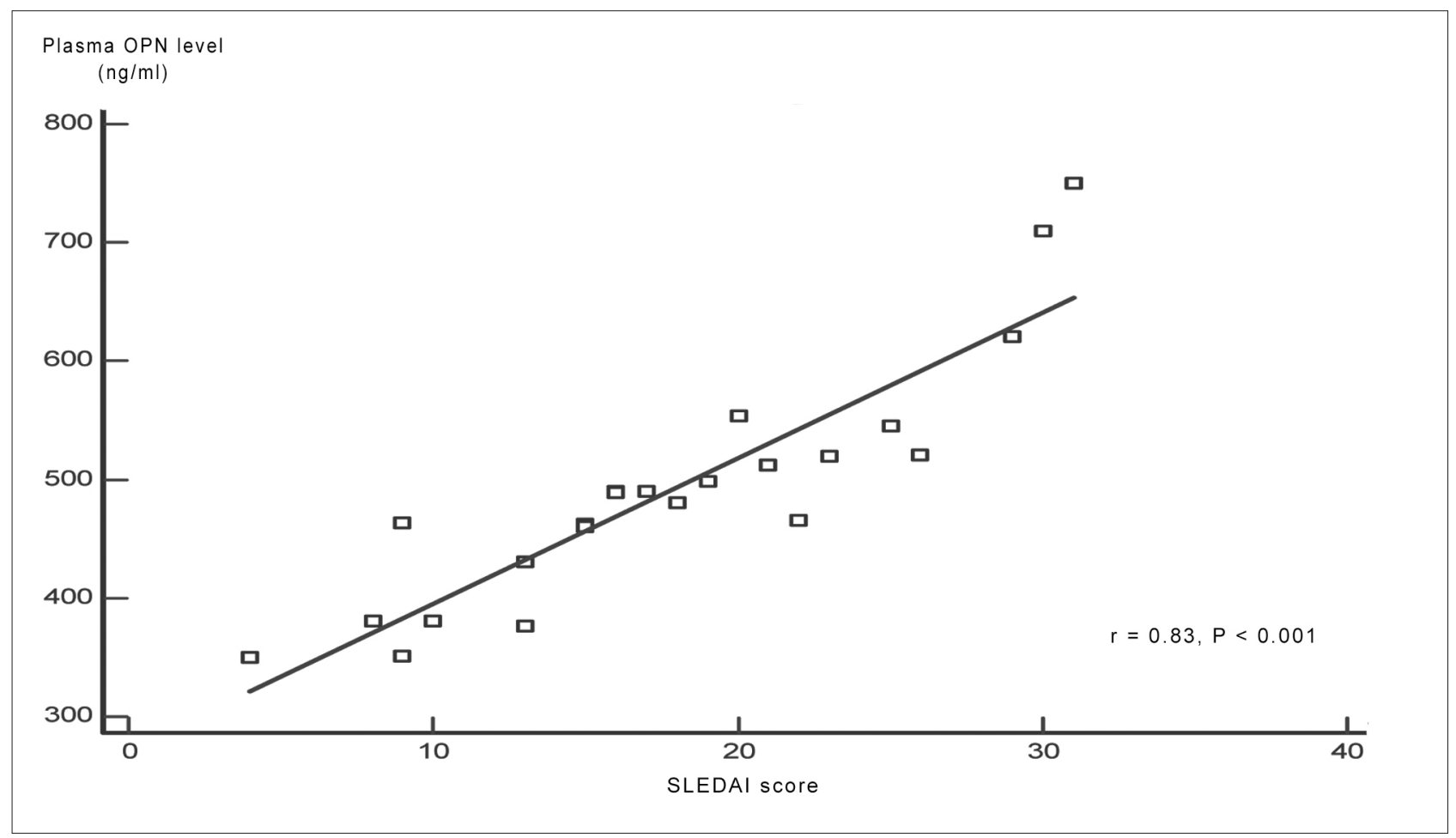

irreversible organ damage, such as renal failure in SLE [29]. Chan et al reported that patients with active lupus nephritis have a predominant Th1 type of T-lymphocyte activation [30].

IL-18 is a proinflammatory cytokine related to the IL-1 family. It plays an important role in innate immunity and Th1 response to toxic shock, and shares functional similarities with IL-12 [6]. Wong et al reported significantly elevated IL-18 concentration in SLE patients compared with control [31]. These results suggest that Th1 predominance is important in SLE disease development. OPN is a cytokine that has been newly implicated in autoimmunity and other inflammatory processes [22]. We measured both IL-18 and OPN cytokine level in SLE patients to correlate it with the disease activity.

In this study, the plasma concentration of the Th1 cytokine IL-18 was significantly elevated in SLE patients compared to control, and this elevation was positively correlated to SLEDAI. These results are in agreement with other reports [32] which proposed that IL-18 can enhance the expression of Fas ligand in NK cells and CTL, causing Fas-mediated apoptosis in epithelial cells and tissue damage. Moreover, IL-18 in combination with other pro-inflammatory cytokines, including IL-1 and TNF-alpha may be important cytokines for the initiation and progression of catabolic response and fever in SLE [5].

In contrast to those results, Robak et al found no difference in the levels of IL-18 between active and inactive SLE [33]. This may be explained by the fact that SLE is a heterogeneous disease in which variability in the mean levels of certain cytokines is expected. In addition, cytokines level in the plasma may not reflect the locally high concentration produced in lymphoid tissues. Cytokines in the plasma may be bound to proteins or form complexes with soluble receptors or auto antibodies, which may affect their detection [34].

In this study, the plasma concentration of the cytokine OPN was significantly increased in SLE patients compared to controls, and correlated positively with SLEDAI. Moreover, it was significantly and positively correlated with the plasma concentration of IL-18 in SLE patients. These findings concur with the findings reported by Wong et al [32].

In conjunction with the inflammatory activities of IL-18, such as the induction of Th1 cytokine IFN-alpha and activation of $\mathrm{T}$ cells, NK cells and cytotoxic $\mathrm{T}$ lymphocytes [35], OPN can enhance the Th1-mediated inflammatory process, activation of NK and T cells, and macrophage migration during an exacerbation of SLE. 
Acting together with other pro-inflammatory cytokines, including IL-1 and TNF-alpha, OPN may be an important cytokine for initiating and perpetuating the Th1 immune response and renal derangement in SLE.

Apart from Th1-cell activation, OPN can also activate macrophage adhesion [36], migration [30] and cytokine release [10]. Our present findings therefore support the attribution of increased ex-vivo production of OPN to the activation of macrophages and T cells in the inflammatory process during SLE exacerbation.

\section{Conclusion}

This study confirms the association between the production of OPN and IL-18 and SLE disease activity. This suggests a crucial role for the Th1 cytokines in the inflammatory processes and tissue damage in SLE disease. In view of these results, OPN and IL-18 may also serve as potential markers for monitoring of SLE disease activity and therapeutic efficacy.

\section{References}

1. Mills JA. Systemic lupus erythematosus. N Engl J Med.1994;330(26):1871-9.

2. Amital H, Shoenfeld Y. Autoimmunity and autoimmune diseases such as systemic lupus erythematosus. In: Lahita RG, ed. Systemic lupus erythematosus. 3rd ed. London: Academic Press; 1999.

3. Viallard JF, Pellegrin JL, Ranchin V, Schaeverbeke T, Dehais J, Longy-Boursier M, Ragnaud JM, Leng B, Moreau JF. Th1 (IL-2, interferongamma(IFN-gamma)) and Th2 (IL-10, IL-4) cytokine production by peripheral blood mononuclear cells (PBMC) from patients with systemic lupus erythematosus (SLE). Clin Exp Immunol. 1999;115(1):189-95.

4. Wong CK, Li EK, Ho CY, Lam CW. Elevation of plasma interleukin-18 concentration is correlated with disease activity in systemic lupus erythematosus. Rheumatology (Oxford). 2000;39(10):1078-81.

5. Dinarello CA.IL-18:ATH1-inducing, proinflammatory cytokine and new member of the IL-1 family. J Allergy Clin Immunol. 1999;103(1 Pt1):11-24.

6. Fehniger TA, Shah MH, Turner MJ, VanDeusen JB, Whitman SP, Cooper MA, Suzuki K, Wechser M, Goodsaid F, Caligiuri MA. Diferential cytokine and chemokine gene expression by human NK cells following activation with IL-18 or IL-15 in combination with IL-12: implications for the innate immune response. J Immunol. 1999;162(8):4511-20.
7. Dao T, Ohashi K, Kayano T, Kurimoto M, Okamura H. Interferon-gamma-inducing factor, a novel cytokine, enhances Fas ligand-mediated cytotoxicity of murine T helper cells. Cell Immunol. 1997;173(2):230-5.

8. Chabas D, Baranzini SE, Mitchell D, Bernard CC, Rittling SR, Denhardt DT, Sobel RA, Lock C, Karpuj M, Pedotti R, Heller R, Oksenberg JR, Steinman L. The influence of the proinflammatory cytokine, osteopontin, on autoimmune demyelinating disease. Science. 2001;294(5547):1731-5.

9. Giachelli CM, Steitz S. Osteopontin: a versatile regulator of inflammation and biomineralization. Matrix Biol. 2000;19(7):615-22.

10. Ashkar S, Weber GF, Panoutsakopoulou V, Sanchirico ME, Jansson M, Zawaideh S, Rittling SR, Denhardt DT, Glimcher MJ, Cantor H. Eta-1 (osteopontin): an early component of type-1 (cell-mediated) immunity. Science. 2000;287(5454):860-4.

11. Weber GF, Ashkar S, Cantor H. Interaction between CD44 and osteopontin as a potential basis for metastasis formation. Proc Assoc Am Physicians. 1997;109(1):1-9.

12. Liaw L, Birk DE, Ballas CB, Whitsitt JS, Davidson JM, Hogan BL. Altered wound healing in mice lacking a functional osteopontin gene. J Clin Invest. 1998;101(7):1468-78.

13. Bautista DS, Xuan JW, Hota C, Chambers AF, Harris JF. Inhibition of Arg-Gly-Asp (RGD)-mediated cell adhesion to osteopontin by a monoclonal antibody against osteopontin. J Biol Chem. 1994;269(37):23280-5.

14. Qin LX, Tang ZY. Recent progress in predictive biomarkers for metastatic recurrence of human hepatocellular carcinoma: a review of the literature. J Cancer Res Clin Oncol. 2004;130(9):497-513.

15. Vogt MH, Lopatinskaya L, Smits M, Polman CH, Nagelkerken L. Elevated osteopontin levels in active relapsing-remitting multiple sclerosis. Ann Neurol. 2003;53(6):819-22.

16. Chiocchetti A, Indelicato M, Bensi T, Mesturini R, Giordano M, Sametti S, Castelli L, Bottarel F, Mazzarino MC, Garbarini L, Giacopelli F, Valesini G, Santoro C, Dianzani I, Ramenghi U, Dianzani U. High levels of osteopontin associated with polymorphisms in its gene are a risk factor for development of autoimmunity/ lymphoproliferation. Blood. 2004;103(4):1376-82.

17. Masutani K, Akahoshi M, Tsuruya K, Tokumoto M, Ninomiya T, Kohsaka T, Fukuda K, Kanai H, Nakashima H, Otsuka T, Hirakata H. Predominance of Th1 immune response in diffuse proliferative lupus nephritis. Arthritis Rheum. 2001;44(9):2097-106. 
18. Ohshima S, Yamaguchi N, Nishioka K, Mima T, Ishii T, Umeshita-Sasai M, Kobayashi H, Shimizu M, Katada Y, Wakitani S, Murata N, Nomura S, Matsuno H, Katayama R, Kon S, Inobe M, Uede T, Kawase I, Saeki Y. Enhanced local production of osteopontin in rheumatoid joints. J Rheumatol. 2002;29(10):2061-7.

19. Wong CK, Lit LC, Tam LS, Li EK, Lam CW. Elevation of plasma osteopontin concentration is correlated with disease activity in patients with systemic lupus erythematosus. Rheumatology (Oxford). 2005;44(5):602606.

20. Bombardier C, Gladman DD, Urowitz MB, Caron D, Chang $\mathrm{CH}$. Derivation of the SLEDAI. A disease activity index for lupus patients. The Committee on Prognosis Studies in SLE. Arthritis Rheum. 1992;35(6):630-40.

21. Tan EM, Cohen AS, Fries JF, Masi AT, McShane DJ, Rothfield NF, Schaller JG, Talal N, Winchester RJ. The 1982 revised Criteria for the classification of systemic lupus eryth- ematosus. Arthritis Rheum. 1982;25(11):1271-7.

22. Mohan C, Adams S, Stanik V, Datta SK. Nucleosome: a major immunogen for pathogenic autoantibody-inducing T cells of lupus. J Exp Med. 1993;177(5):1367-81.

23. Viallard JF, Pellegrin JL, Ranchin V, Schaeverbeke T, Dehais J, Longy-Boursier M, Ragnaud JM, Leng B, Moreau JF. Th1 (IL-2, interferon-gamma (IFN-gamma)) and Th2(IL-10, IL-4) cytokine production by peripheral blood mononuclear cells (PBMC) from patients with systemic lupus erythematosus (SLE). Clin Exp Immunol. 1999;115(1):189-95.

24. Hagiwara E, Gourley MF, Lee S, Klinman DK. Disease severity in patients with systemic lupus erythematosus correlates with an increased ratio of interleukin-10: interferon-gamma-secreting cells in the peripheral blood. Arthritis Rheum. 1996;39(3):379-85.

25. Yu C, Sun K, Tsai C, Tsai Y, Tsai S, Huang D, Han S, Yu H. Expression of Th1/Th2 cytokine mRNA in peritoneal exudative polymorphonuclear neutrophils and their effects on mononuclear cell Th1/Th2 cytokine production in MRL-lpr/lpr mice. Immunology. 1998;95(3):480-7.

26. Tokano $\mathrm{Y}$, Morimoto S, Kaneko H, Amano H, Nozawa K, Takasaki Y, Hashimoto H. Levels of IL-12 in the sera of patients with systemic lupus erythematosus
(SLE)-relation to Th1- and Th2-derived cytokines. Clin Exp Immunol.1999;116(1):169-73.

27. Davas EM, Tsirogianni A, Kappou I, Karamitsos D, Economidou I, Dantis PC. Serum IL-6, TNFalpha, p55 srTNFalpha, p75srTNFalpha, srIL-2alpha levels and disease activity in systemic lupus erythematosus. Clin Rheumatol. 1999;18(1):17-22.

28. al-Janadi M, al-Balla S, al-Dalaan A, Raziuddin S. Cytokine profile in systemic lupuserythematosus, rheumatoid arthritis, and other rheumatic diseases. J Clin Immunol. 1993;13(1):58-67.

29. Aringer M, Smolen JS. Tumour necrosis factor and other proinflammatory cytokines in systemic lupus erythematosus: a rationale for therapeutic intervention. Lupus. 2004;13(5):344-7.

30. Chan RW, Lai FM, Li EK, Tam LS, Chow KM, Li PK, Szeto CC. Imbalance of Th1/Th2 transcription factors in patients with lupus nephritis. Rheumatology. 2006;45(8):951-7.

31. Wong CK, Ho CY, Li EK, Lam CW. Elevation of proinflammatory cytokine (IL-18, IL-17, IL-12) and Th2 cytokine (IL-4) concentrations in patients with systemic lupus erythematosus. Lupus. 2000;9(3):589-93.

32. Wong CK, Li EK, Ho CY, Lam WK. Elevation of plasma IL-18 concentration is correlated with disease activity in SLE. Rhematolgy (Oxford). 2000;39(10):107881.

33. Robak E, Robak T, Woziniacka A, Zak-Perlisch M, Sysa-Jedrzejowska A, Stepien H. Proinflammatory interferon-gamma-inducing monokines (interleukin-12, interleukin-18, interleukin-15): Serum profile in patients with SLE. Eur Cytokine Net. 2002;13(3):364-8.

34. Horwitz DA, Stohl W, Gray JD. T lymphocytes, natural killer cells, cytokines, and immune regulation. In: Wallace DJ, Hahn BH, eds. Dubois'lupus erythematosus. Baltimore, MD: Williams and Wilkins; 1997. p. 155-94.

35.DinarelloCA.IL-18:aTH1-inducing, proinflammatory cytokine and new member of the IL-1 family. J Allergy Clin Immunol. 1999;103(1 Pt 1):11-24.

36. Giachelli CM, Lombardi D, Johnson RJ, Murry CE, Almeida M. Evidence for a role of osteopontin in macrophage infiltration in response to pathological stimuli in vivo. Am J Pathol. 1998;152(2):353-8. 